\title{
The Application of Mix Delphi-AHP Method in Identification and Prioritization Competencies Needed by National Tax Collector
}

\author{
Ikhwan Muslim Nasution $^{1}$, Yeni Absah ${ }^{2}$, Isfenti Sadalia ${ }^{2}$ \\ ${ }^{1,2}$ Master of Management Study Program, Postgraduate School, Universitas Sumatera Utara, Medan, Indonesia.
}

Corresponding Author: Ikhwan Muslim Nasution

\begin{abstract}
This study aimed to identify and prioritize competencies needed by the national tax collector. This study was conducted in two regional offices of the Directorate General of Taxes that consists of sixteen tax offices. Fourteen former national tax collector's top performers from the 2017 to 2020 periods participated as the expert panel in two online Delphi surveys on different rating scales (fivepoint and nine-point) to clarify the list of competencies identified by the researcher from literature reviews and documentation studies. The Delphi panel reached a consensus for sixteen competencies in both surveys representing three categories: managerial, technical, and sociocultural competencies. The Analytic Hierarchy Process (AHP) was used to analyze the priority of competencies. Forty-six respondents, which consist of the National Tax Collector and the Head of the Audit, Appraisal, and Tax Collector Section, were participated in the AHP survey. The result shows that technical competency was the top priority among the category of competencies followed by sociocultural and managerial competencies. Based on the overall scores, the competencies' priority rankings from the top to the lowest, respectively, are sociocultural adaptation, soft collection, adhesive and unifying the nation, hard collection, tax knowledge, identification and profiling of tax bearer, integrity, compliance risk management, ICT literacy, communication, result orientation, decision-making, teamwork, public service, managing change, and developing self and others.
\end{abstract}

Keywords: Competency, Delphi, Analytic Hierarchy Process, Tax Collector

\section{INTRODUCTION}

Human, both individually or collectively, is the most important capital for the organization's sustainability. According to Mayo ${ }^{[1]}$, every individual in an organization not only acts as an organizational resource, but they are also an asset and a stakeholder. The achievement of the organization's vision, mission, and goals is determined by how maximum the people owned by the organization provide valueadded to all organization's stakeholders. Individually, people lend their human capital that includes their ability, commitment, knowledge, and experience to the organization. Collectively, human capital including the way they work together and relates both inside and outside the organization. In return, they receive financial and non-financial rewards.

Directorate General of Taxes (DGT) is a government organization under the Ministry of Finance of the Republic of Indonesia (RI). The DGT Head Office is located in Jakarta. The total number of DGT employees as of September 2019 was 44,784 employees spread over 609 work units. A total of 38,490 employees are in structural positions, and 6,294 employees are in functional positions. ${ }^{[2]}$

One of the DGT's main tasks is to collect government revenues from the taxation sector. Based on the 2019 DGT 
Performance Report, the portion of tax revenue to total government revenues in the 2019 State Budget reached $82.5 \%$. ${ }^{[3]}$ The proportion of tax revenue to total government revenues in the 2014 to 2019 State Budget provides in Table 1. The high dependence on government revenues source from the taxation sector is the biggest challenge for DGT.

Table 1 The Portion of Tax Revenue to Total Government Revenues in State Budget ${ }^{[3]}$

\begin{tabular}{|l|l|}
\hline Year & Portion (\%) \\
\hline 2014 & 74,0 \\
\hline 2015 & 82,3 \\
\hline 2016 & 82,6 \\
\hline 2017 & 80,6 \\
\hline 2018 & 81,4 \\
\hline 2019 & 82,5 \\
\hline
\end{tabular}

Another major challenge is Indonesia's tax ratio which is still below the target set in the 2015-2019 National Medium-Term Development Plan. This issue had become one of the main focuses in the Policy and Strategy Directions contained in the 2015-2019 Ministry of Finance Strategic Plan. ${ }^{[4]}$ The tax ratio illustrates how much tax revenue was obtained from the national economy to the Gross Domestic Product (GDP) in one fiscal year. In 2019, Indonesia's tax ratio target was $16 \%$, only $10.69 \%$ had been realized. [5] DGT implements extensification and intensification tax strategies to increase the tax ratio. To be successfully implemented, these strategies must be supported by an effective integrated tax system that consists of supervision, inspection, investigation, and tax collection.

Tax collection is a series of actions taken so that the tax bearer pays off taxes payable and tax collection fees. These actions include issuing a Warning Letter, notification of a Distress Warrant, proposing prevention, carrying out confiscation, publishing an auction announcement for the confiscated assets, carrying out hostage, and carrying out instant and lump sum collections. ${ }^{[6]}$ Taxes payable are taxes that have to be paid, including administrative sanctions in the form of interest, fines, or increases as stated in a Notice of Tax Collection, Notice of Tax Assessment, or similar letter, based on the tax laws and regulations. ${ }^{[6]}$

The disbursement of tax receivables decreased in the 2017 - 2019 periods, while the allowance for uncollectible tax receivables increased in the same period (Figure 1). DGT had collected government revenues from tax receivables that amounted to Rp24.07 trillion in 2017, Rp16.64 trillion in 2018, and Rp16.56 trillion in 2019. ${ }^{[3,7,8]}$ Allowance for uncollectible tax receivables amounted to Rp26.43 trillion in 2017, Rp41.10 trillion in 2018, and Rp44.89 trillion in 2019. ${ }^{\text {[9-11] }}$ This condition should be a concern of policymakers to prevent the increase in the balance of tax receivables at the end of each fiscal year. If not immediately taken care of properly, this will further increase the risk of uncollected tax receivables.

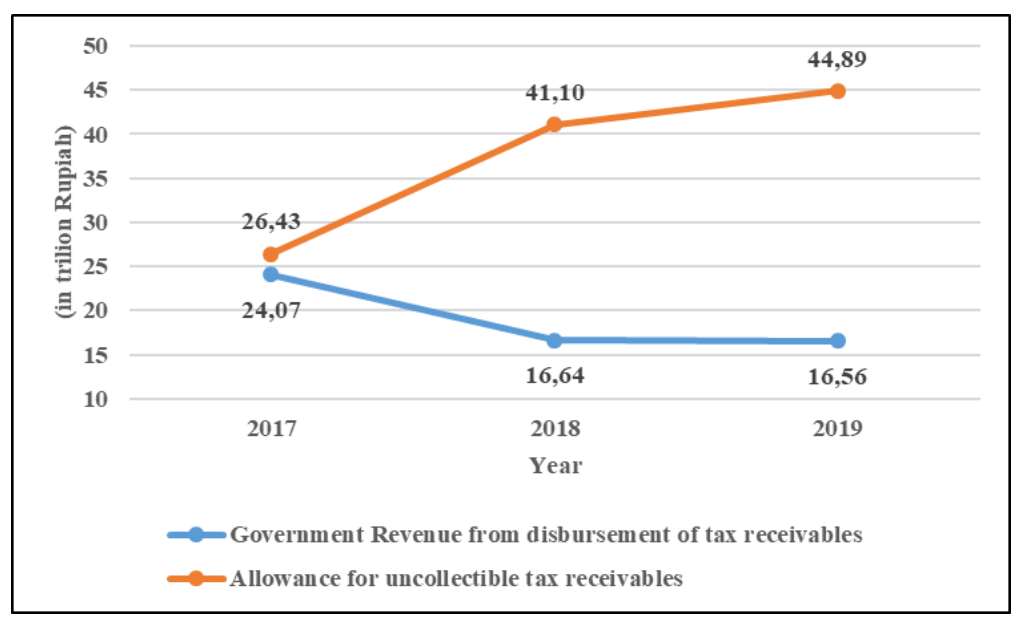

Figure 1 The Disbursement of Tax Receivables and Allowance for Uncollectible Tax Receivables Source: Processed from DGT Performance Report ${ }^{[3,7,8]}$ and Central Government Financial Report (Audited) ${ }^{[9-11]}$ 
DGT requires employees who have the necessary competencies in carrying out their duties to achieve government revenues from the disbursement of tax receivables and to support an increase in the tax ratio. Therefore, it is necessary to have a competency standard for the national tax collector. Competency standards can be used as a guideline in the selection process, training and development, performance appraisal, succession planning, and comprehensive evaluation of ongoing training and development programs to get the best people that the organization needed. [12]

Based on these research problems, the objectives of this study were to identify and analyze the prioritization competencies needed by national tax collectors.

\section{LITERATURE REVIEW}

The concept of competency-based human resource management has become a generally accepted practice today since David McClelland [13], through the publication of his research Testing for Competence Rather Than for "Intelligence", for the first time proposed competency as an important differentiator of individual performance. ${ }^{[14]}$ This was considered provocative at the time because it argued that personal competency was more important in predicting job success than traditional psychometric tests such as intellectual intelligence and aptitude tests. [15] The competency approach in human resource management is based on a series of processes of identifying, defining, and measuring individual differences in relation to certain job-related concepts, especially the critical abilities needed to achieve successful performance in a job. ${ }^{[16]}$

Boyatsiz ${ }^{[14]}$ defined competency as a capability or ability and stated that the basis for the concept of competency is the theory of performance. Torkkeli and Tuominen ${ }^{[17]}$ defined competency as the integration and coordination of capabilities to exploit resources. According to the Human Resource Management Framework of the United Nations Industrial Development Organization (UNIDO), competency is a combination of skills, knowledge, and behaviors that leads to effective performance on the job. ${ }^{[18]}$

According to Regulation Number 38 of 2017 of Minister of State Apparatus Empowerment and Bureaucratic Reform of the Republic of Indonesia on State Apparatus Position Competency Standards, there are three categories of competency needed by state apparatus, namely managerial, technical and sociocultural competencies. ${ }^{[19]}$ Managerial competency is knowledge, skills, abilities, and other characteristics (KSAOs) to lead or manage organizational units. Technical competency is KSAOs specifically related to the technical field of the position. Sociocultural competency is KSAOs related to the experience of interacting with a pluralistic society in terms of religion, ethnicity and culture, behavior, national insight, ethics, values, morals, emotions, and principles, which must be fulfilled by each position holder to obtain work results in accordance with the role, function, and position. ${ }^{[19]}$

\section{Managerial Competencies Integrity}

Integrity is an attitude to choose ethical actions. ${ }^{[12]}$ Horton et al. ${ }^{[20]}$ define integrity as an attitude that consistently maintains social and ethical standards in words and actions. Ministry of State Apparatus Empowerment and Bureaucratic Reform defines integrity as consistently behaving by organizational values, norms, ethics, and being honest in relationships with management, co-workers, direct subordinates, and stakeholders, creating a high ethical culture, being responsible for actions, decisions, or the risks that come with them. ${ }^{[19]}$

\section{Teamwork}

Teamwork implies a genuine intention to work cooperatively with others and be part of a team. ${ }^{[12]}$ Teamwork is the ability to establish, foster, and maintain effective working relationships, having a 
commitment to help each other in completing tasks and optimizing all resources to achieve the organization's strategic goals. ${ }^{[19]}$

\section{Communication}

The ability to communicate openly is one of the competencies needed in managing an organization. [12] Communication is the ability to explain views and ideas clearly, systematically, and appropriately accompanied by logical arguments, both orally and in writing, ensure understanding, active and effective listening, persuading, and convincing others to achieve organizational goals. ${ }^{[19]}$

\section{Result Orientation}

Result orientation competency is the ability to maintain a high personal commitment to complete tasks, be reliable, be responsible, and identify risks and opportunities systematically by paying attention to the relationship between planning and result. ${ }^{[19]}$

\section{Public Service}

Public service competency is the ability to carry out government tasks, development, and activities to fulfill public service needs in a professional, transparent, and following service standards that are objective, neutral, impartial, nondiscriminatory, and not influenced by personal interests, groups, or political parties. ${ }^{[19]}$

\section{Developing Self and Others}

Developing self and others is the ability to increase knowledge and skills, inspire others increasing their knowledge and skills that are relevant to work and longterm career development, encourage a willingness to learn throughout life, provide advice, feedback, and guidance to help others to develop their potential. ${ }^{[19]}$

\section{Managing Change}

Managing change is the ability to adapt to new or changing situations and not rely excessively on old methods and processes, take action to support and implement change initiatives, lead change efforts, and take personal responsibility to ensure changes are implemented effectively. [19]

\section{Decision-making}

Decision-making includes the ability to specify goals and constraints, generate alternatives, consider risks, evaluate, and choose the best option. ${ }^{[12]}$ Decision-making defines as making good decisions promptly and confidently after considering the precautionary principle, formulated systematically and thoroughly based on various information, alternative solutions to problems and their consequences, and are responsible for the decisions taken. ${ }^{[19]}$

\section{Technical Competencies Hard Collection}

Hard collection competency is the ability to carry out actions so that the tax bearer pays off tax payable and tax collection cost by admonishing or warning, carrying out an instant and simultaneous collection, notifying distress warrant, proposing prevention, carrying out confiscations, carrying out hostages, and selling confiscated assets following procedures and regulations. ${ }^{[6,21]}$

\section{Soft Collection}

Soft collection competency is the ability to take a persuasive approach to the tax bearer to convince, persuade, and arouse the awareness of the tax bearer to pay off the tax payable through visits, letters, emails, telephones, invitations, and other relevant and lawful means.

\section{Identification and Profiling of Tax Bearer}

Identification and profiling of tax bearer competency is the ability to identify and collect specific data and information related to Tax Bearers which includes identity, address and domicile, list of assets and proof of ownership, deed of establishment and or deed of change of corporate Taxpayer, annual tax report, monthly tax report, filing of Taxpayer legal remedies, and other relevant documents with their efforts or with the assistance of internal and external parties. ${ }^{[22]}$ 


\section{Compliance Risk Management}

Compliance risk management is the ability to manage risk in tax collection activities by specifies treatment alternatives for Tax bearers based on the Priority List of Tax Collection Actions which includes the Action Priority List and the Disbursement of Tax Receivable Priority List. ${ }^{[8]}$

\section{ICT Literacy}

ICT literacy is the ability to use computers, information devices, and communication technologies professionally. ICT literacy consists of computer literacy, information literacy, digital literacy, and internet literacy. ${ }^{[23]}$

\section{Tax Knowledge}

Tax authorities should have competency in the fields of tax policy, tax administration, and taxation legislation. [24] The term tax legislation includes the ability to demonstrate an understanding of the scope of tax laws and their legal definitions; ability to apply tax law provisions in daily work; support the study and preparation of tax regulations; and able to implement, interpret, and provide tax advice whenever needed. ${ }^{[25]}$ In this study, tax knowledge defines as the ability to acquire and apply knowledge, expertise, and experience related to tax regulations, policies, and administration in a professional manner.

\section{Sociocultural Competencies}

\section{Adhesive and Unifying the Nation}

Adhesive and unifying the nation competency define as:

1) ability to promote tolerance, openness, and sensitivity to the individual or group differences in society;

2) ability to become the government representatives in uniting the community and building psychological-social relationships with the community to create strong attachments between the State Civil Apparatus and stakeholders as well as among the stakeholders themselves; and

3) ability to maintain, develop, and realize a sense of unity and integrity in the life of the Indonesian people, nation, and state. ${ }^{[19]}$

\section{Sociocultural Adaptation}

Sociocultural adaptation is the ability to adapt and negotiate daily activities in a new cultural environment. ${ }^{[26,27]}$

\section{Conceptual Framework}

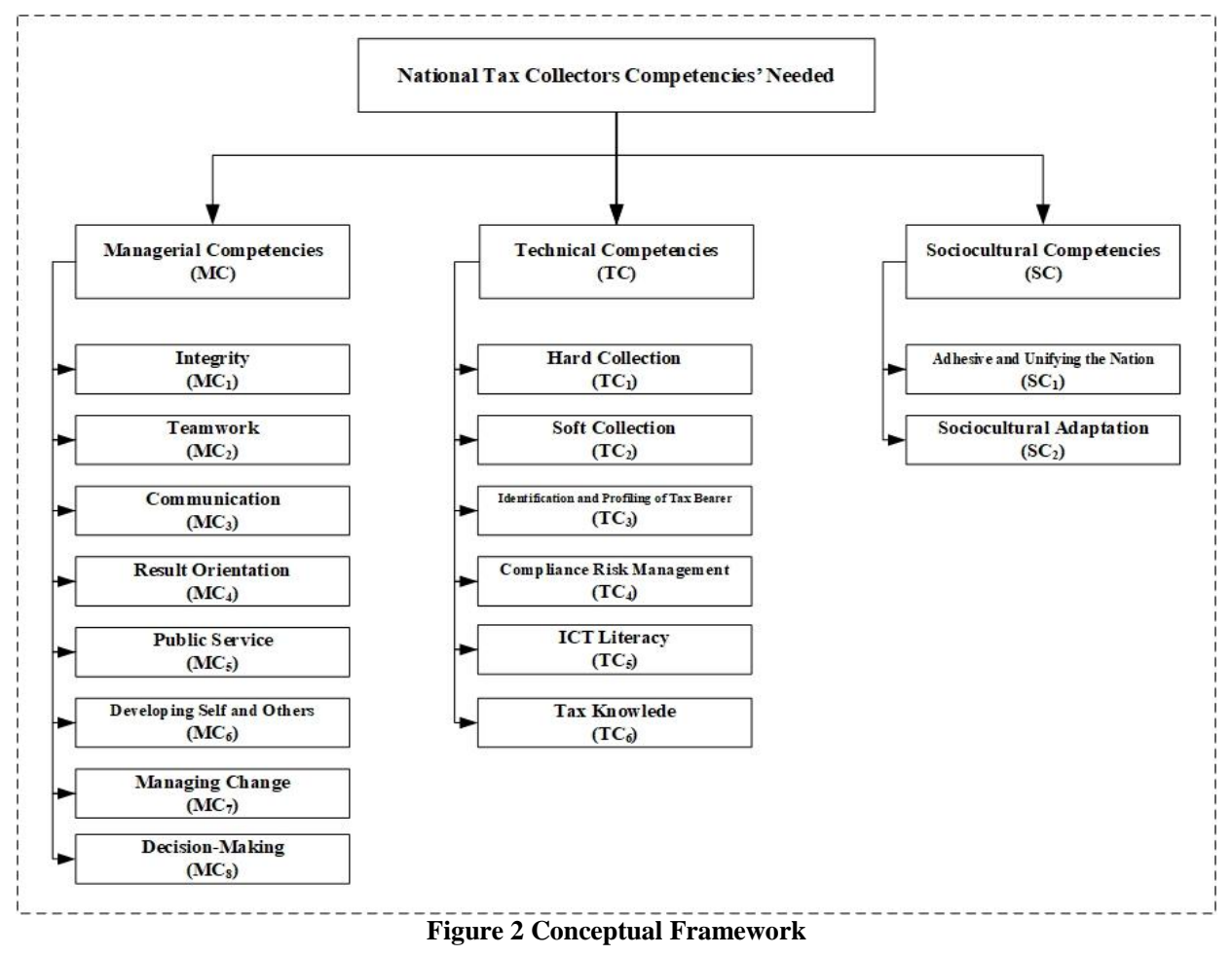




\section{MATERIALS AND METHODS Delphi Method}

Delphi is a method used to obtain reliable consensus opinions from a group of experts. ${ }^{[28]}$ There has been a debate among academics and researchers about the definition of an expert involved in a Delphi panel related to the potential bias in the panelist composition selection process [29] that can affect the results obtained. ${ }^{[30]}$ Some researchers identify an expert as an informed individual, a specialist, or someone who has the knowledge and experience necessary to participate in a Delphi panel. ${ }^{[31,32]}$ Experts involved in the Delphi panel must have in-depth knowledge and expertise in a specific field with the research topic so that it is not relevant to include people who have expertise outside the research topic as Delphi panelists. ${ }^{[33]}$ To avoid potential bias and considering that it is still difficult to define experts from external parties who have specific knowledge, experience, and expertise in the field of technical tax collection, the panelists in this study only consists of employees who have received awards as the best national tax collector in 2017 to 2020 periods in the North Sumatra Regional Tax Office I and II. In line with the suggestion by Spencer and Spencer ${ }^{[12]}$, superior performers should be involved in the competency identification process.

Using the Delphi method in research does not depend on statistical samples trying to represent a population. ${ }^{[34]}$ The number of panelists in the Delphi method varies, and there is no standard provision on how much the minimum or maximum number is. ${ }^{[32,35,36]}$ In this study, 14 employees who had been the best National Tax Collector in the North Sumatra Regional Tax Office I and II in the 2017 to 2020 periods had invited as panelists.

Panelists were requested to respond to the form of opinions to closed statements on five Likert scales (1: strongly disagree; 5: strongly agree) for the Delphi I questionnaire and nine Likert scales for the Delphi II questionnaire (1: strongly disagree; 9: strongly agree). In this study, panelists reached a consensus for competency in the Delphi I questionnaire if at least $51 \%$ of panelists agreed (voted $4+$ ), the mean of the answers was more than 3.0, and the interquartile range was less than or equal to 1.0. Panelists reached a consensus for competency in the Delphi II questionnaire if at least $51 \%$ of panelists agreed (voted 7+), the mean of the answers was more than 5.0, and the interquartile range was less than or equal to 3.0. If differences occurred in consensus obtained from the two questionnaires, the questionnaires would be revised and resubmitted in the next round. Only competencies that have obtained consensus approval will be analyzed using the AHP method in the next stage.

\section{Analytic Hierarchy Process}

Thomas L. Saaty developed the AHP method in the 1970s. ${ }^{[37]}$ AHP is theory and methodology used to perform relative measurements. ${ }^{[38]}$ The AHP method is designed for situations where ideas, feelings and emotions that influence the decisionmaking process are quantified to provide a numerical scale for prioritizing alternatives. [39]

Table 2 Fundamental Scale of Absolute Number ${ }^{[45]}$

\begin{tabular}{|c|c|c|}
\hline $\begin{array}{ll}\text { Intensity } & \text { of } \\
\text { Importance } & \end{array}$ & Definition & Explanation \\
\hline 1 & Equal importance & Two activities contribute equally to the objective \\
\hline 2 & Weak or slight & \\
\hline 3 & Moderate importance & Experience and judgment slightly favor one activity over another \\
\hline 4 & Moderate plus & \\
\hline 5 & Strong importance & Experience and judgment strongly favor one activity over another \\
\hline 6 & Strong plus & \\
\hline 7 & $\begin{array}{l}\text { Very strong or demonstrated } \\
\text { importance }\end{array}$ & $\begin{array}{l}\text { An activity is favored very strongly over another; its dominance } \\
\text { demonstrated in practice }\end{array}$ \\
\hline 8 & Very, very strong & \\
\hline 9 & Extreme importance & $\begin{array}{l}\text { The evidence favoring one activity over another is of the highest possible } \\
\text { order of affirmation }\end{array}$ \\
\hline
\end{tabular}


The number of respondents used in studies using the AHP method varies, and there are no standard provisions regarding sample size or respondents in the AHP method. ${ }^{[40-44]}$ Respondents of this study consist of National Tax Collectors and the Heads of the Inspection, Assessment, and Collection Section at the small and medium tax offices in two regional tax offices in the North Sumatra area. Respondents were requested to rate the relative priorities scaling from 1 to 9 (Table 2) between several pairs of competencies in the AHP questionnaires.

This study used the Aggregation Individual Judgment (AIJ) approach to combined respondents' answers. The geometric means of all respondents' final answers, with a maximum individual consistency ratio of $10 \%$, were used to form a new aggregation matrix. The matrix was consistent if the group's consistency ratio did not exceed the maximum of $10 \%$.

\section{RESULTS \& DISCUSSIONS Delphi Panelists' Demographic Characteristics}

Fourteen national tax collector top performers of the 2017-2020 periods participated as the expert panel in two online Delphi questionnaires on different rating scales (five-point and nine-point) to clarify the list of competencies identified by the researcher from literature reviews and documentation studies. Based on gender, $85.71 \%$ of the panelists were male, while $14.29 \%$ were female. In terms of age group, $28.57 \%$ of the panelists were less than or equal to 25 years old, $28.57 \%$ were more than 25 up to 35 years old, $42.86 \%$ were more than 35 up to 45 years old, and none of them was above 45 years old. Eight panelists $(47.14 \%)$ have undergraduate degrees, while six $(42.86 \%)$ have graduate degrees. Based on the tenure, $35.71 \%$ of the panelists have served less than or equal to five years, $14.29 \%$ have more than five up to ten years, $21.43 \%$ have more than ten up to fifteen years, and $28.57 \%$ have more than fifteen years at the DGT.

\section{Consensus}

The Delphi panel reached a consensus for sixteen competencies in both questionnaires representing three categories: managerial, technical, and sociocultural competencies (Table 3). No differences occurred in consensus for both questionnaires that used different Likert scales. The results of this study did not support the findings of Lange et al. ${ }^{[46]}$ that stated different scales lead to different consensus. Managerial competencies consist of integrity $\left(\mathrm{MC}_{1}\right)$, teamwork $\left(\mathrm{MC}_{2}\right)$, communication $\left(\mathrm{MC}_{3}\right)$, result orientation $\left(\mathrm{MC}_{4}\right)$, public service $\left(\mathrm{MC}_{5}\right)$, developing self and others $\left(\mathrm{MC}_{6}\right)$, managing change $\left(\mathrm{MC}_{7}\right)$, and decision-making $\left(\mathrm{MC}_{8}\right)$. Technical competencies consist of hard collection $\left(\mathrm{TM}_{1}\right)$, soft collection $\left(\mathrm{TM}_{2}\right)$, identification and profiling tax bearer $\left(\mathrm{TM}_{3}\right)$, compliance risk management $\left(\mathrm{TM}_{4}\right)$, ICT literacy $\left(\mathrm{TM}_{5}\right)$, and tax knowledge $\left(\mathrm{TM}_{6}\right)$. Sociocultural competencies consist of adhesive and unifying the nation competency $\left(\mathrm{SC}_{1}\right)$ and sociocultural adaptation competency $\left(\mathrm{SC}_{2}\right)$. These competencies will be analyzed using the AHP method.

\begin{tabular}{|c|c|c|c|c|c|c|}
\hline & & & le 3 Concenst & & & \\
\hline \multirow[t]{2}{*}{ Competencies } & \multicolumn{3}{|c|}{ Delphi I } & \multicolumn{3}{|c|}{ Delphi II } \\
\hline & Mean & IQR & majority rule & mean & IQR & majority rule \\
\hline $\mathrm{MC}_{1}$ & 4,93 & 0,00 & $100,00 \%$ & 8,93 & 0,00 & $100,00 \%$ \\
\hline $\mathrm{MC}_{2}$ & 4,86 & 0,00 & $100,00 \%$ & 8,79 & 0,25 & $100,00 \%$ \\
\hline $\mathrm{MC}_{3}$ & 5,00 & 0,00 & $100,00 \%$ & 9,00 & 0,00 & $100,00 \%$ \\
\hline $\mathrm{MC}_{4}$ & 4,36 & 1,00 & $92,86 \%$ & 8,36 & 1,00 & $92,86 \%$ \\
\hline $\mathrm{MC}_{5}$ & 4,29 & 1,00 & $85,71 \%$ & 8,07 & 2,00 & $85,71 \%$ \\
\hline $\mathrm{MC}_{6}$ & 4,86 & 0,00 & $100,00 \%$ & 8,71 & 1,00 & $100,00 \%$ \\
\hline $\mathrm{MC}_{7}$ & 4,50 & 1,00 & $92,86 \%$ & 8,36 & 1,00 & $92,86 \%$ \\
\hline $\mathrm{MC}_{8}$ & 4,71 & 1,00 & $100,00 \%$ & 8,50 & 1,00 & $92,86 \%$ \\
\hline $\mathrm{TC}_{1}$ & 4,79 & 0,25 & $100,00 \%$ & 8,64 & 0,25 & $92,86 \%$ \\
\hline $\mathrm{TC}_{2}$ & 4,86 & 0,00 & $100,00 \%$ & 8,86 & 0,00 & $100,00 \%$ \\
\hline $\mathrm{TC}_{3}$ & 4,93 & 0,00 & $100,00 \%$ & 9,00 & 0,00 & $100,00 \%$ \\
\hline
\end{tabular}


Ikhwan Muslim Nasution et.al. The application of mix Delphi-AHP method in identification and prioritization competencies needed by national tax collector.

\begin{tabular}{|l|l|l|l|l|l|l|}
\hline \multicolumn{7}{|c|}{ Table 3 Continued... } \\
\hline $\mathrm{TC}_{4}$ & 4,71 & 1,00 & $100,00 \%$ & 8,71 & 0,25 & $100,00 \%$ \\
\hline $\mathrm{TC}_{5}$ & 4,64 & 1,00 & $100,00 \%$ & 8,64 & 1,00 & $100,00 \%$ \\
\hline $\mathrm{TC}_{6}$ & 4,86 & 0,00 & $100,00 \%$ & 8,86 & 0,00 & $100,00 \%$ \\
\hline $\mathrm{SC}_{1}$ & 4,71 & 1,00 & $100,00 \%$ & 8,50 & 1,00 & $100,00 \%$ \\
\hline $\mathrm{SC}_{2}$ & 4,93 & 0,00 & $100,00 \%$ & 8,86 & 0,00 & $100,00 \%$ \\
\hline
\end{tabular}

\section{AHP Respondents' Demographic Characteristics}

The number of respondents was 46 people with a participation rate of $88.46 \%$ (46/52). Respondents consisted of thirtythree National Tax Collectors and thirteen Heads of Audit, Appraisal, and Tax Collection Section. Based on gender, $82.61 \%$ of the respondents were male, while $17.39 \%$ were female. In terms of age group, $19.57 \%$ of the respondents were less than or equal to 25 years old, $26.09 \%$ were more than 25 up to 35 years old, $34.78 \%$ were more than 35 up to 45 years old, and $18.75 \%$ were over 45 years old. Twenty-two respondents $(47.83 \%)$ have undergraduate degrees, twelve respondents $(26.09 \%)$ have graduate degrees, and twelve respondents $(26.09 \%)$ have postgraduate degrees.

\section{Prioritization of Competencies}

The analysis started by calculating the consistency index and consistency ratio of each respondent. Respondents' final answers with a maximum individual consistency ratio of $10 \%$ will be combined using the AIJ approach to analyze the priority of the competencies at the group level. Respondents filled out a questionnaire consisting of four pair comparisons sets, namely managerial competency, technical competency, socio-cultural competency, and the competency categories.

Priority vector, maximum eigenvalue $\left(\boldsymbol{\lambda}_{\max }\right)$, consistency index (CI), and consistency ratio (CR) for managerial competencies normalized pairwise comparison matrix are as provided in Table 4. The CR value is $0.28 \%$, below the upper limit of $10 \%$. Therefore, the matrix is accepted to be a consistent matrix.

Table 4 Managerial Competencies Normalized Pairwise Comparison Aggregation Matrix

\begin{tabular}{|l|l|l|l|l|l|l|l|l|l|}
\hline & $\mathbf{M C}_{\mathbf{1}}$ & $\mathbf{M C}_{\mathbf{2}}$ & $\mathbf{M C}_{\mathbf{3}}$ & $\mathbf{M C}_{\mathbf{4}}$ & $\mathbf{M C}_{\mathbf{5}}$ & $\mathbf{M C}_{\mathbf{6}}$ & $\mathbf{M C}_{\mathbf{7}}$ & $\mathbf{M C}_{\mathbf{8}}$ & priority vector \\
\hline $\mathbf{M C}_{1}$ & 0.283 & 0.337 & 0.281 & 0.298 & 0.257 & 0.255 & 0.265 & 0.277 & 0.282 \\
\hline $\mathrm{MC}_{2}$ & 0.083 & 0.099 & 0.120 & 0.107 & 0.109 & 0.103 & 0.108 & 0.095 & 0.103 \\
\hline $\mathrm{MC}_{3}$ & 0.143 & 0.116 & 0.142 & 0.158 & 0.137 & 0.151 & 0.151 & 0.138 & 0.142 \\
\hline $\mathrm{MC}_{4}$ & 0.117 & 0.113 & 0.110 & 0.123 & 0.141 & 0.134 & 0.141 & 0.135 & 0.127 \\
\hline $\mathrm{MC}_{5}$ & 0.107 & 0.087 & 0.100 & 0.085 & 0.097 & 0.106 & 0.096 & 0.088 & 0.096 \\
\hline $\mathrm{MC}_{6}$ & 0.079 & 0.068 & 0.067 & 0.065 & 0.065 & 0.071 & 0.065 & 0.080 & 0.070 \\
\hline $\mathrm{MC}_{7}$ & 0.079 & 0.068 & 0.069 & 0.065 & 0.075 & 0.082 & 0.074 & 0.079 & 0.074 \\
\hline $\mathrm{MC}_{8}$ & 0.110 & 0.112 & 0.111 & 0.099 & 0.119 & 0.096 & 0.101 & 0.108 & 0.107 \\
\hline $\mathrm{Total}$ & 1.000 & 1.000 & 1.000 & 1.000 & 1.000 & 1.000 & 1.000 & 1.000 & 1.000 \\
\hline $\boldsymbol{\lambda}_{\max }=8.028 ; \mathrm{CI}$ & $\mathbf{9}$ \\
\hline
\end{tabular}

Priority vector, $\boldsymbol{\lambda}_{\max }, \mathrm{CI}$, and CR for technical competencies normalized pairwise comparison matrix are as provided in Table
5. The CR value is $0.24 \%$, below the upper limit of $10 \%$. Therefore, the matrix is accepted to be a consistent matrix.

Table 5 Technical Competencies Normalized Pairwise Comparison Aggregation Matrix
\begin{tabular}{|l|l|l|l|l|l|l|l|}
\hline & TC $_{\mathbf{1}}$ & $\mathbf{T C}_{\mathbf{2}}$ & $\mathbf{T C}_{\mathbf{3}}$ & $\mathbf{T C}_{\mathbf{4}}$ & $\mathbf{T C}_{\mathbf{5}}$ & $\mathbf{T C}_{\mathbf{6}}$ & priority vector \\
\hline $\mathrm{TC}_{1}$ & 0.213 & 0.224 & 0.209 & 0.185 & 0.222 & 0.221 & 0.212 \\
\hline $\mathrm{TC}_{2}$ & 0.208 & 0.219 & 0.245 & 0.212 & 0.229 & 0.207 & 0.220 \\
\hline $\mathrm{TC}_{3}$ & 0.167 & 0.146 & 0.164 & 0.197 & 0.169 & 0.161 & 0.167 \\
\hline $\mathrm{TC}_{4}$ & 0.145 & 0.129 & 0.104 & 0.125 & 0.114 & 0.129 & 0.124 \\
\hline $\mathrm{TC}_{5}$ & 0.093 & 0.092 & 0.094 & 0.106 & 0.097 & 0.102 & 0.097 \\
\hline $\mathrm{TC}_{6}$ & 0.174 & 0.190 & 0.184 & 0.175 & 0.170 & 0.180 & 0.179 \\
\hline $\mathrm{Total}$ & 1.000 & 1.000 & 1.000 & 1.000 & 1.000 & 1.000 & 1.000 \\
\hline $\boldsymbol{\lambda}_{\max }=6.015 ; \mathrm{CI}=0.003 ; \mathrm{CR}=0.24 \%$ \\
\hline
\end{tabular}


The priority vector for sociocultural competencies normalized pairwise comparison matrix is as provided in Table 6. According to Saaty ${ }^{[45]}$, "every 2-by-2 positive reciprocal matrix is consistent".

Table 6 Sociocultural Competencies Normalized Pairwise Comparison Aggregation Matrix

\begin{tabular}{|l|l|l|l|}
\hline & $\mathbf{S C}_{\mathbf{1}}$ & $\mathbf{S C}_{\mathbf{2}}$ & priority vector \\
\hline $\mathrm{SC}_{1}$ & 0.361 & 0.361 & 0.361 \\
\hline $\mathrm{SC}_{2}$ & 0.639 & 0.639 & 0.639 \\
\hline Total & 1.000 & 1.000 & 1.000 \\
\hline
\end{tabular}

Priority vector, $\boldsymbol{\lambda}_{\max }, \mathrm{CI}$, and CR for the competency categories normalized pairwise comparison matrix are as provided in Table 7. The CR value is $0.01 \%$, below the upper limit of $10 \%$. Therefore, the matrix is accepted to be a consistent matrix.

Table 7 The Competency Categories Normalized Pairwise Comparison Aggregation Matrix

\begin{tabular}{|l|l|l|l|l|}
\hline & MC & TC & SC & priority vector \\
\hline MC & 0.217 & 0.219 & 0.214 & 0.217 \\
\hline TC & 0.482 & 0.487 & 0.491 & 0.487 \\
\hline SC & 0.301 & 0.294 & 0.296 & 0.297 \\
\hline Total & 1.000 & 1.000 & 1.000 & 1.000 \\
\hline & $\lambda_{\max }=3.00010 ; \mathrm{CI}=0.00005 ; \mathrm{CR}=0.01 \%$ \\
\hline
\end{tabular}

Competency priority rankings based on priority vector values are as presented in Table 8. The top priority of managerial competencies is integrity, followed by communication, result orientation, decisionmaking, teamwork, public service, managing change, and developing self and others, respectively. Technical competencies' top priority is the soft collection, followed by hard collection, tax knowledge, identification and profiling of tax bearer, compliance risk management, and ICT literacy, respectively. Sociocultural adaptation is the sociocultural competencies' top priority, followed by adhesive and unifying the nation. The competency categories' top priority is technical competency followed, respectively, by sociocultural competency and managerial competency.

Table 8 The Rankings of Priority

\begin{tabular}{|c|c|c|c|c|c|c|c|c|}
\hline \multirow[t]{2}{*}{ Ranking } & \multicolumn{2}{|l|}{ MC } & \multicolumn{2}{|l|}{ TC } & \multicolumn{2}{|l|}{ SC } & \multicolumn{2}{|l|}{ Categories } \\
\hline & $\mathbf{M C}_{\mathbf{i}}$ & priority vector & $\mathbf{T C}_{\mathrm{i}}$ & priority vector & $\mathbf{S C}_{\mathbf{i}}$ & priority vector & Categories & priority vector \\
\hline 1 & $\mathrm{MC}_{1}$ & 0,2816 & $\mathrm{TC}_{2}$ & 0,2200 & $\mathrm{SC}_{2}$ & 0,6394 & $\mathrm{TC}$ & 0,4867 \\
\hline 2 & $\mathrm{MC}_{3}$ & 0,1420 & $\mathrm{TC}_{1}$ & 0,2122 & $\mathrm{SC}_{1}$ & 0,3606 & SC & 0,2967 \\
\hline 3 & $\mathrm{MC}_{4}$ & 0,1267 & $\mathrm{TC}_{6}$ & 0,1790 & - & - & $\mathrm{MC}$ & 0,2166 \\
\hline 4 & $\mathrm{MC}_{8}$ & 0,1071 & $\mathrm{TC}_{3}$ & 0,1671 & - & - & - & - \\
\hline 5 & $\mathrm{MC}_{2}$ & 0,1030 & $\mathrm{TC}_{4}$ & 0,1243 & - & - & - & - \\
\hline 6 & $\mathrm{MC}_{5}$ & 0,0957 & $\mathrm{TC}_{5}$ & 0,0973 & - & - & - & - \\
\hline 7 & $\mathrm{MC}_{7}$ & 0,0739 & - & - & - & - & - & - \\
\hline 8 & $\mathrm{MC}_{6}$ & 0,0701 & - & - & - & - & - & - \\
\hline
\end{tabular}

The competencies' overall rankings based on the overall scores obtained from the multiplication of the priority vector value of each competency with each priority vector value of the competency category are as presented in Table 9. Based on the overall scores, the competencies' priority rankings from the top to the lowest, respectively, are sociocultural adaptation, soft collection, adhesive and unifying the nation, hard collection, tax knowledge, identification and profiling of tax bearer, integrity, compliance risk management, ICT literacy, communication, result orientation, decision-making, teamwork, public service, managing change, and developing self and others.

Table 9 The Competencies' Overall Rankings

\begin{tabular}{|l|l|l|l|l|l|}
\hline Competency & Priority Vector of Competency & Category & Priority Vector of Category & Overall Score & Ranking \\
\hline $\mathrm{SC}_{2}$ & 0,6394 & $\mathrm{SC}$ & 0,2967 & 0,1897 & 1 \\
\hline $\mathrm{TC}_{2}$ & 0,2200 & $\mathrm{TC}$ & 0,4867 & 0,1071 & 2 \\
\hline $\mathrm{SC}_{1}$ & 0,3606 & $\mathrm{SC}$ & 0,2967 & 0,1070 & 3 \\
\hline $\mathrm{TC}_{1}$ & 0,2122 & $\mathrm{TC}$ & 0,4867 & 0,1033 & 4 \\
\hline $\mathrm{TC}_{6}$ & 0,1790 & $\mathrm{TC}$ & 0,4867 & 0,0871 & 5 \\
\hline $\mathrm{TC}_{3}$ & 0,1671 & $\mathrm{TC}$ & 0,4867 & 0,0813 & 6 \\
\hline $\mathrm{MC}_{1}$ & 0,2816 & MC & 0,2166 & 0,0610 & 7 \\
\hline $\mathrm{TC}_{4}$ & 0,1243 & $\mathrm{TC}$ & 0,4867 & 0,0605 & 8 \\
\hline
\end{tabular}


Ikhwan Muslim Nasution et.al. The application of mix Delphi-AHP method in identification and prioritization competencies needed by national tax collector.

\begin{tabular}{|c|c|c|c|c|c|}
\hline \multicolumn{6}{|c|}{ Table 9 Continued... } \\
\hline $\mathrm{TC}_{5}$ & 0,0973 & $\mathrm{TC}$ & 0,4867 & 0,0474 & 9 \\
\hline $\mathrm{MC}_{3}$ & 0,1420 & $\mathrm{MC}$ & 0,2166 & 0,0307 & 10 \\
\hline $\mathrm{MC}_{4}$ & 0,1267 & $\mathrm{MC}$ & 0,2166 & 0,0274 & 11 \\
\hline $\mathrm{MC}_{8}$ & 0,1071 & $\mathrm{MC}$ & 0,2166 & 0,0232 & 12 \\
\hline $\mathrm{MC}_{2}$ & 0,1030 & $\mathrm{MC}$ & 0,2166 & 0,0223 & 13 \\
\hline $\mathrm{MC}_{5}$ & 0,0957 & $\mathrm{MC}$ & 0,2166 & 0,0207 & 14 \\
\hline $\mathrm{MC}_{7}$ & 0,0739 & $\mathrm{MC}$ & 0,2166 & 0,0160 & 15 \\
\hline $\mathrm{MC}_{6}$ & 0,0701 & $\mathrm{MC}$ & 0,2166 & 0,0152 & 16 \\
\hline
\end{tabular}

\section{CONCLUSIONS}

The study results can be summarized as follows:

1) The panelists reached a consensus for sixteen competencies representing three categories: managerial, technical, and sociocultural competencies. Managerial competencies consist of integrity, teamwork, communication, result orientation, public service, developing self and others, managing change, and decision-making.

Technical competencies consist of hard collection, soft collection, identification and profiling of tax bearer, compliance risk management, ICT literacy, and tax knowledge. Sociocultural competencies consist of adhesive and unifying the nation competency and sociocultural adaptation competency.

2) Results obtained from priority analysis using the AHP method are the priority rankings for managerial competencies, technical competencies, sociocultural competencies, the competency categories, and overall. The top priority of managerial competencies is integrity, followed by communication, result orientation, decision-making, teamwork, public service, managing change, and developing self and others, respectively. Technical competencies' top priority is the soft collection, followed by hard collection, tax knowledge, identification and profiling of tax bearer, compliance risk management, and ICT literacy, respectively. Sociocultural adaptation is the sociocultural competencies' top priority, followed by adhesive and unifying the nation. The competency categories' top priority is technical competency followed, respectively, by sociocultural competency and managerial competency. Based on the overall scores, the competencies' priority rankings from the top to the lowest, respectively, are sociocultural adaptation, soft collection, adhesive and unifying the nation, hard collection, tax knowledge, identification and profiling of tax bearer, integrity, compliance risk management, ICT literacy, communication, result orientation, decision-making, teamwork, public service, managing change, and developing self and others.

\section{Acknowledgement: None}

\section{Conflict of Interest: None}

\section{Source of Funding: None}

\section{REFERENCES}

1. Mayo A. The human value of the enterprise: Valuing people as assets: Monitoring, measuring, managing. London: Nicholas Brealey Publishing; 2001.

2. DGT. Strategic Plan of the Directorate General of Taxes years 2020-2024, Decree of the Director-General of Taxes Number 389/PJ/2020.

3. DGT. The 2019 DGT performance report.

4. Ministry of Finance. Strategic Plan of the Ministry of Finance years 2015-2019, Decree of the Minister of Finance Number 466/KMK.01/2015.

5. Ministry of Finance. Strategic Plan of the Ministry of Finance years 2020-2024, Regulation of the Minister of Finance Number 77/PMK.01/2020.

6. RI. Tax Collection by Distress Warrant, Law Number 19 of 1997.

7. DGT. The 2017 DGT performance report.

8. DGT. The 2018 DGT performance report.

9. RI. The 2017 Central Government Financial Report (Audited). 
10. RI. The 2018 Central Government Financial Report (Audited).

11. RI. The 2019 Central Government Financial Report (Audited).

12. Spencer LM, Spencer SM. Competence at work: Models for superior performance. New York: John Wiley \& Sons; 1993.

13. McClelland DC. Testing for competence rather than for "intelligence". American Psychologist. 1973; 28(1): 1-14.

14. Boyatzis RE. Competencies in the $21 \mathrm{st}$ century. Journal of Management Development. 2008; 27 (1): 5-12.

15. Skorková Z. Competency models in public sector. Procedia - Social and Behavioral Sciences. 2016; 230: 226-234.

16. Vakola M, Soderquist KE, Prastacos GP. Competency management in support of organisational change. International Journal of Manpower. 2007; 28(3/4): 260-275.

17. Torkkeli M, Tuominen M. (2002). The contribution of technology selection to core competencies. International Journal Production Economics. 2002; 77(3): 271284.

18. United Nations Industrial Development Organization. Human Resource Management Framework, UNIDO Secretariat Administrative Instruction Number UNIDO/AI/2015/01.

19. Ministry of State Apparatus Empowerment and Bureaucratic Reform. State Apparatus Position Competency Standards, Regulation of Ministry of State Apparatus Empowerment and Bureaucratic Reform Number 38 of 2017.

20. Horton S, Hondeghem A, Farnham D. Competency management in the public sector: European variations on a theme. International Institute of Administrative Science monographs volume 19. Amsterdam: IOS Press; 2002.

21. RI. Amendments to Law Number 19 of 1997 concerning Tax Collection by Distress Warrant, Law Number 19 of 2000.

22. DGT. The implementation of prevention in the context of tax collection, Circular Letter of the Director-General of Taxes Number 09/PJ/2020.

23. Saleh B. Literasi teknologi informasi dan komunikasi (TIK) masyarakat di kawasan Mamminasata. Jurnal Pekomnas. 2015; 18(3): 151-160.

24. Rabiyah U, Suryani A, Karim A. The effect of awareness, fiscus services and taxation knowledge on taxpayer compliance at Madya Makassar KPP. International Journal of Innovation Scientific Research and Review. 2021; 03(01): 797-799.

25. European Union. EU tax competency framework: Competencies dictionary. Luxembourg: Publications Office of the European Union; 2019.

26. Ward C, Kennedy A. The measurement of sociocultural adaptation. International Journal of Intercultural Relations. 1999; 23(4): 659-677.

27. Wilson J, Ward C, Fischer R. Beyond culture learning theory: What can personality tell us about cultural competence?. Journal of Cross-Cultural Psychology. 2013; 44(6): 900-927.

28. Dalkey N, Helmer O. An experimental application of the Delphi method to the use of experts. Management Science. 1963; 9(3): 458-467.

29. Bloor M, Sampson H, Baker S, Dahlgren K. Useful but no Oracle: reflections on the use of a Delphi Group in a multi-methods policy research study. Qualitative Research. 2015; 15(1): 57-70.

30. Keeney S, Hasson F, McKenna HP. A critical review of the Delphi technique as a research methodology for nursing. International Journal of Nursing Studies. 2001; 38(2): 195-200.

31. Goodman CM. The Delphi technique: a critique. Journal of Advanced Nursing. 1987; 12(6): 729-734.

32. Clayton MJ. Delphi: A technique to harness expert opinion for critical decision-making tasks in education. Educational Psychology: An International Journal of Experimental Educational Psychology. 1997; 17(4): 373386.

33. Martino, J. P. (1993). Technological forecasting for decision making (3rd ed.). McGraw-Hill, Inc.

34. Okoli C, Pawlowski SD. The Delphi method as a research tool: An example, design considerations and applications. Information \& Management. 2004; 42(1): 15-29.

35. Avella JR. Delphi panels: Research design, procedures, advantages, and challenges. International Journal of Doctoral Studies. 2016; 11: 305-321.

36. Loo R. The Delphi method: a powerful tool for strategic management. Policing: An International Journal. 2002; 25(4): 762-769. 
37. Donegan HA, Dodd FJ, McMaster TBM. A new approach to AHP decision-making. The Statistician. 1992, 41(3): 295-302.

38. Brunelli M. Introduction to the Analytic Hierarchy Process. Cham: Springer International Publishing; 2015.

39. Taha HA. Operations research: an introduction. 10th ed. Harlow: Pearson; 2017.

40. Horváthová P, Čopíková A, Mokrá K. Methodology proposal of the creation of competency models and competency model for the position of a sales manager in an industrial organisation using the AHP method and Saaty's method of determining weights. Economic Research-Ekonomska Istraživanja. 2019; 32(1): 2594-2613.

41. Miciuła I, Nowakowska-Grunt J. Using the AHP method to select an energy supplier for household in Poland. Procedia Computer Science. 2019; 159: 2324-2334.

42. Ocampo L, Alinsub J, Casul RA, Enquig G, Luar M, Panuncillon N, et al. Public service quality evaluation with SERVQUAL and AHP-TOPSIS: A case of Philippine government agencies. Socio-Economic Planning Sciences. 2019; 68: 100604.

43. Park Y. Analytic Hierarchy Process for decision making in kinesiology: An application in selecting athletic shoes for walking [Dissertation]. Champaign, Illinois: University of Illinois Urbana-Champaign, 2011.

44. Fang C-H, Chang S-T, Chen G-L. Competency development among Taiwanese healthcare middle manager: A test of the AHP approach. African Journal of Business Management. 2010; 4(13): 2845-2855.

45. Saaty TL. Decision making - The Analytic Hierarchy and Network Processes (AHP/ANP). Journal of Systems Science and Systems Engineering. 2004; 13(1): 135.

46. Lange T, Kopkow C, Lützner J, Günther K$\mathrm{P}$, Gravius S, Scharf H-P, et al. Comparison of different rating scales for the use in Delphi studies: Different scales lead to different consensus and show different testretest reliability. BMC Medical Research Methodology. 2020, 20(28).

How to cite this article: Nasution IM, Absah Y, Sadalia I. The application of mix Delphi-AHP method in identification and prioritization competencies needed by national tax collector. International Journal of Research and Review. 2021; 8(10): 154-165. DOI: https://doi.org/10. 52403/ijrr.20211020 